\title{
The Victorian Medical Show
}

Previously published at www.cmaj.ca

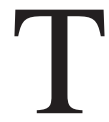
he protagonist in Brian Moore's 1975 Governor General Awardwinning novel, The Great Victorian Collection, wakes one morning to discover that his dream of owning the most-extensive collection ever of Victorian antiquities has materialized in dazzling glory in a parking lot beside his motel — the downside is that it's up to him to look after it. This is a role that retired registered nurse Nancy MacLeod has taken on willingly as she has collected more than 200 pieces of 19th-century medical memorabilia. And like The Great Victorian Collection, she too displays her pieces: Dressed in period costume she reenacts the part of a "medical practitioner" of that era. Using audience members as "patients," she "treats" their various ailments by bloodletting, amputation and the like.

Last year, MacLeod, who lives in Kitchener, Ont., took her show on the road 176 times in Ontario, mostly to nursing homes, but also historical sites and community groups. "The elderly don't just want to be entertained they want to learn things as well," she says.

Her interest is a synthesis of her interest in nursing and medicine and long-time love of history. In the late 1970s she acquired her first piece, an invalid feeder cup. Today her artifacts range from a travelling pharmacy kit to a syphilis syringe (which was filled

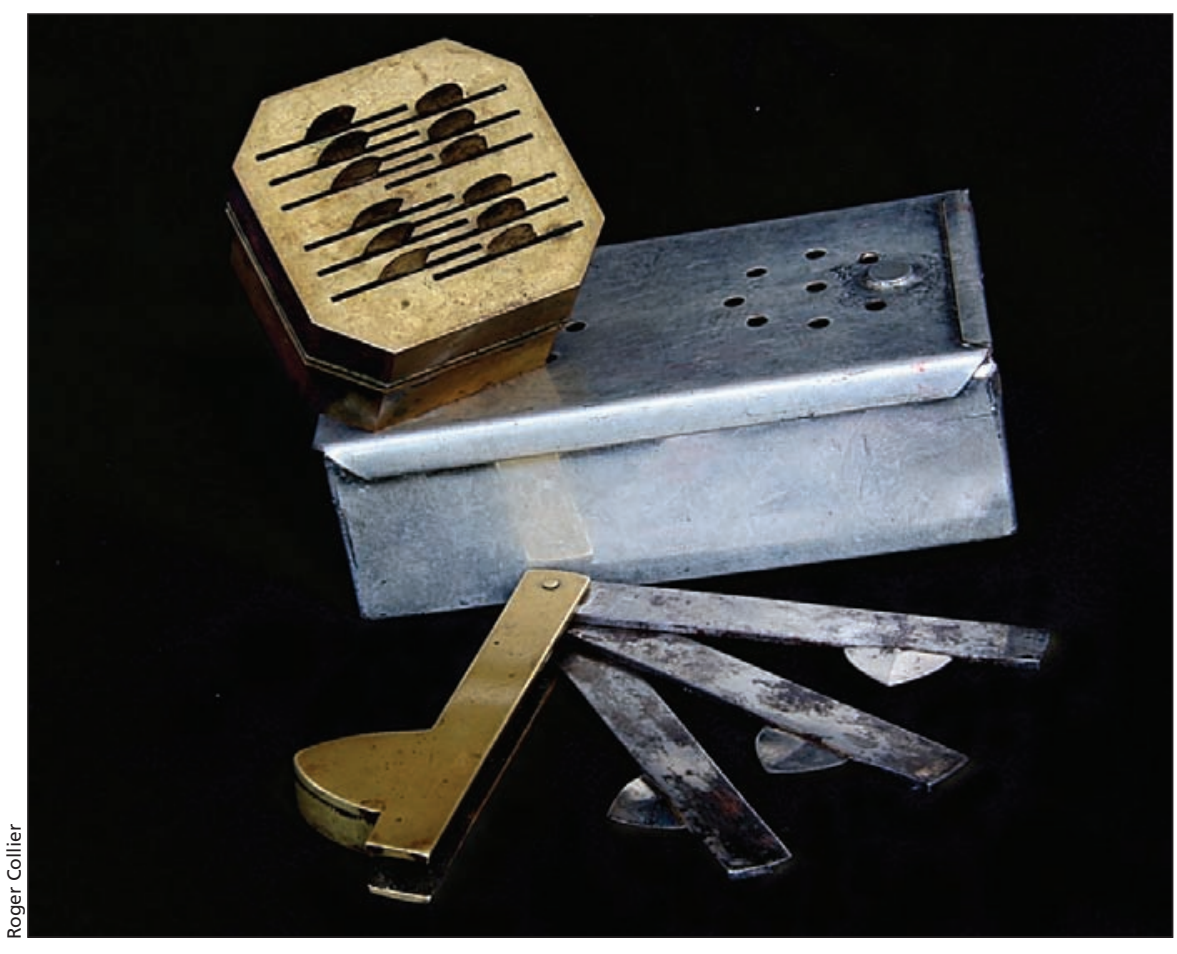

Pictured above, top, is a scarifator from the 1850s, which was used for bloodletting. When the trigger is pulled, 12 razor blades come down and cut the skin and underlying vein. At the centre of photo is a steel reproduction leech box (modelled after one from 1800); leeches were used to clean wounds. At the bottom of photo is a fleam from the 1850 s, also used for bloodletting.

She combs antique stores and thrift shops, occasionally scoring spectacular finds, such as a medical dictionary from 1850 that she bought along with a mitt full of novels for $\$ 2$ at her local Value Village.

Her collection of medical memorabilia and Victorian fashion, gradually

\section{McLeod combs antique stores and thrift} shops, occasionally scoring spectacular finds.

with diluted silver nitrate and injected into the urethra), bloodletting instruments to an enema pump (c. 1855) called The Irrigator, which may have also been used for embalming. grew through the years, then, in 1994, a patient told her about historical reenactments of the Civil War and MacLeod travelled to the United States to have a look. She decided they needed a period medical unit. Her first persona was a Grey Nun and then she became a Confederate nurse leading a unit of eight. Her collecting picked up. Ninety per cent of her pieces are authentic; the reproduction pieces, including an amputation/surgeons kit with multiple knives and bullet forceps, a trephine kit and slip (bed) pan, were acquired for her Civil War re-enactments.

The move from re-enactment to road show came in 1998 when she staged a private Victorian fashion show and was invited by an activities director at a seniors' home to bring her show to that institution.

MacLeod's shows typically begin with an explanation of the health status of your average citizen in 1850, when 


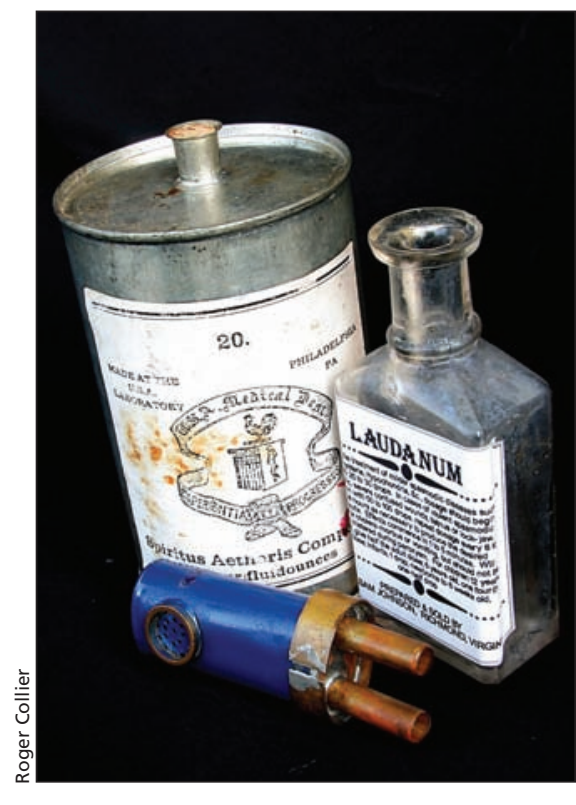

Depicted above is a reproduction of an ether can from 1800, a laudanum bottle from 1850 with a reproduction label and, at the bottom, Dr. Chisholm's inhaler from 1862. Ether was poured on the small sponge inside the inhaler and the two canula would be put in the patient's nose. This was an improvement on the old method of dropping ether onto a cloth over the nose and mouth.

the life-expectancy was around 50. Physician training in the Southern United States consisted of three months of school followed by a two to three year apprenticeship. And medical treatment was based on the concept of the four "humors" in the body: blood, phlegm, yellow bile and black bile. Illness, either physical or mental, resulted

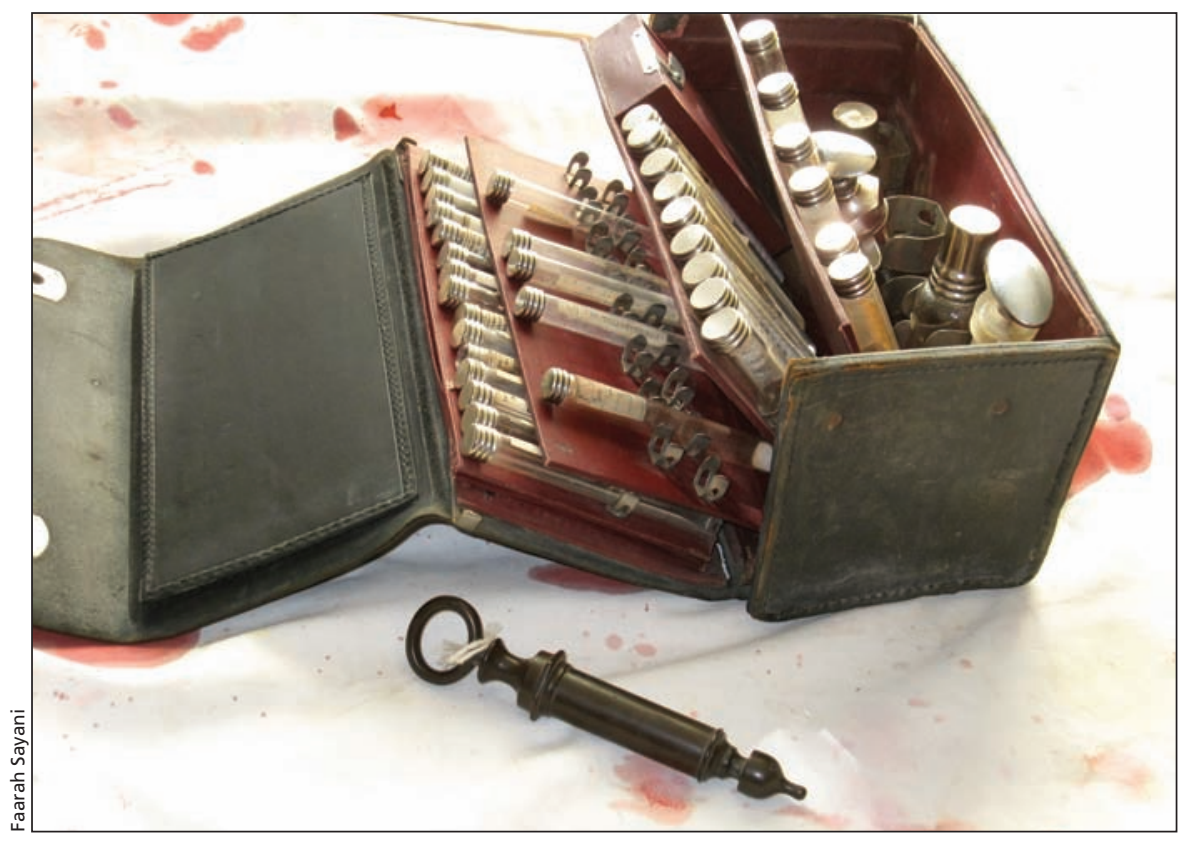

This original apothecary box, c. 1900, contains myriad screw-cap bottles of drug powders, including strychnine. McLeod purchased this at a Mennonite thrift shop. In the foreground is a rubber syphillis syringe dating to 1850, manufactured by the Hanover Rubber Company. It was used to instill diluted silver nitrate or mercury into the uretha, giving rise to the saying: "A night with Venus, a lifetime with Mercury."

when these humors were out of balance. Phlebotomy (bloodletting) reestablished the balance by releasing 16 to 20 ounces of blood; generally it was performed on patients with pneumonia until he or she felt faint, or fell down. No one believed in germs and the only required cleaning of the instruments was an annual oiling of the wooden handles of equipment.

MacLeod's show is pretty convincing as she talks in graphic detail about amputations and bullet wounds. Some- times people have to sit down because they feel faint or leave altogether and she appoints a spotter at school demonstrations. "I enjoy telling stories and seeing people's reactions," says MacLeod. "A lot of people return and ask to hear a story again."

\section{Barbara Sibbald BJ}

Deputy Editor, Analysis and

Humanities

CMAJ

Ottawa, Ont. 